\title{
Depletion risks of essential trace metals in a transboundary drain and its surrounding soil using GIS techniques
}

\author{
Ambreena Javaid ${ }^{1,2}$, Sajid Rashid Ahmad ${ }^{1}$, Rashid Mahmood ${ }^{3, *}$, Khalid Mahmood ${ }^{4}$, \\ Abdul Qadir ${ }^{1}$ and Rida Batool ${ }^{1}$ \\ ${ }^{1}$ College of Earth and Environmental Science, University of the Punjab, Lahore, Pakistan.2Kinnaird College for Women, \\ Lahore, Pakistan; ${ }^{3}$ Department of Soil Science, University of the Punjab, Lahore, Pakistan; ${ }^{4}$ Department of Space Science, \\ University of the Punjab, Lahore, Pakistan. \\ *Corresponding author's e-mail: rashid.iags@pu.edu.pk
}

\begin{abstract}
Hudiara drain, a big sewage water body originating from India, is an important tributary of river Ravi in Pakistan. In present study, role of the drain in build-up/depletion of metal micronutrients $\mathrm{Cu}, \mathrm{Fe}, \mathrm{Mn}$ and $\mathrm{Zn}$ in surrounding agricultural lands has been investigated. Soil samples, up to a vertical distance of $1200 \mathrm{~m}$ on both sides of the drain and drain water samples were collected and analysed for metal micronutrients. Soil analysis results were interpolated by using the best optimized interpolator to generate continuous variation of the selected metals. Further patterns have been identified using proximity stat with consecutive neighbouring zones of $100 \mathrm{~m}$ extent. $\mathrm{Cu}$ and $\mathrm{Mn}$ concentrations were higher in some drain water samples, whereas $\mathrm{Fe}$ and $\mathrm{Zn}$ were found below guidelines in all collected water samples. In adjacent agricultural land the metals did not show uniform dispersal pattern along the drain length. However, vertical pattern of distribution indicated that drain water was controlling $\mathrm{Cu}$ and $\mathrm{Zn}$ concentrations, positively, whereas it was causing a dilution effect on $\mathrm{Fe}$ and Mn build-up in the surrounding agricultural lands.
\end{abstract}

Keywords: copper, iron, manganese, zinc, geographic information system, spatial interpolation, proximity analysis.

\section{INTRODUCTION}

Copper $(\mathrm{Cu})$, Iron $(\mathrm{Fe})$, Manganese $(\mathrm{Mn})$ and $\mathrm{Zinc}(\mathrm{Zn})$ are essential plant micronutrients that perform various vital functions in plant body. They act as cofactors of several enzymes involved in photosynthesis, oxidation-reduction reactions, nitrogen fixation, and metabolism of proteins and carbohydrates etc. (Osman, 2013). Initially, these metal nutrients were enough in most soils of the world to support plant growth. However, intensive exhaustive cropping has resulted in the deficiency of one or more micronutrients particularly in alkaline calcareous soils and hence these need to be applied through fertilizers (Ryan et al., 2013).

On the other hand, owing to irrigation with urban or industrial effluents and other anthropogenic activities, toxic levels of $\mathrm{Cu}, \mathrm{Fe}, \mathrm{Mn}$ and $\mathrm{Zn}$ may be accumulated in agricultural lands to drastically affect plant growth (Wuana and Okieimen, 2011). From polluted soils, high concentrations of these metals may enter the food chain to cause various disorders in human body like anaemia, neurodegeneration in brain, and hair and skin discolorations, dermatitis, and respiration related problems (Shakir et al., 2016). Keeping in view agricultural and environmental importance of these metals, it is necessary to keep an eye on their build up in soils and their possible sources.

Hudiara Drain (HD) is an international drain, which originates from Batala in India. after covering nearly $55 \mathrm{~km}$ on Indian side it enters Pakistan and flows about $63 \mathrm{~km}$ before joining the River Ravi. In terms of latitude, the drain extends from $31^{\circ} 31^{\prime} 4.601 " \mathrm{~N}$ to $31^{\circ} 24^{\prime} 23.612^{\prime \prime} \mathrm{N}$ and in terms of longitude, it extends from $74^{\circ} 36^{\prime} 24.413 " \mathrm{E}$ to $74^{\circ} 6^{\prime} 15.751^{\prime \prime} \mathrm{E}$ in the outskirt of Lahore city with an average annual discharge of about 180 cusecs (Yamin and Ahmad, 2007). It was initially a storm water drain but now a perennial drain, carries untreated sewage water and industrial effluent all the yearlong (Khan et al., 2003). There are about 250 industries of different sizes which throw their discharge in HD on Indian and Pakistani sides (Qureshi and Syed, 2014). The drain water is used for irrigation in adjacent agricultural lands.

Javaid, A., S. R. Ahmad, R. Mahmood, K. Mahmood. 2021. Depletion risks of essential trace metals in a transboundary drain and its surrounding soil using GIS techniques. Pak. J. Agri. Sci. 58:1215-1221. 
In recent years, several studies have been carried out on HD water, adjacent agricultural land, and vegetation. In 2007, in the drain water, concentrations of $\mathrm{Cu}, \mathrm{Fe}, \mathrm{Mn}, \mathrm{Cd}, \mathrm{Cr}$ and $\mathrm{Ni}$ were found higher than the guidelines suggested by WWF for Pakistan (WWF, 2007; Kashif et al., 2009). The concentration of some metals was also found higher than permissible limits in soil and vegetable samples collected from the fields irrigated with the drain water (Kashif et al., 2009). However, in 2003, the drain water had low heavy metal load and $\mathrm{Cu}, \mathrm{Cr}$, and $\mathrm{Cd}$ concentrations in the water were below permissible limits (Khan et al., 2003). Some other studies focus on ground water quality (Khattak et al., 2012), distribution of herbaceous vegetation in surrounding of HD, and impact of irrigation with HD water on plants like Eucalyptus camaldulensis (Shah et al., 2010), Brassica compestris, Psidium guajava (Muhammad et al., 2013) and Spinacia oleracea (Yamin and Ahmad, 2007).

However, there is a knowledge gap about the build-up or depletion of $\mathrm{Cu}, \mathrm{Fe}, \mathrm{Mn}$ and $\mathrm{Zn}$ in agricultural lands adjacent to the drain. In the present study, advanced GIS techniques have been used to identify the role of HD on these micronutrients' status in surrounding soils. The results of the study will help to find the element(s) which need to focus on nutrient management of crops irrigated with water from the drain or from the tube wells installed on aquifer getting its refill possibly from the drain.

\section{MATERIALS AND METHODS}

Study Area: On Pakistan side, HD passes through the southern outskirt of metropolitan Lahore; provincial capital of Punjab and the second largest population unit of Pakistan with semi-arid subtropical climate. It is situated over flat alluvial plains and has a latitudinal extent of $31^{\circ} 15^{\prime} \mathrm{N}-31^{\circ} 45^{\prime} \mathrm{N}$ and longitudinal extent of $74^{\circ} 01^{\prime} \mathrm{E}-74^{\circ} 39^{\prime} \mathrm{E}$. Associations of the study area are given in Fig. 1.

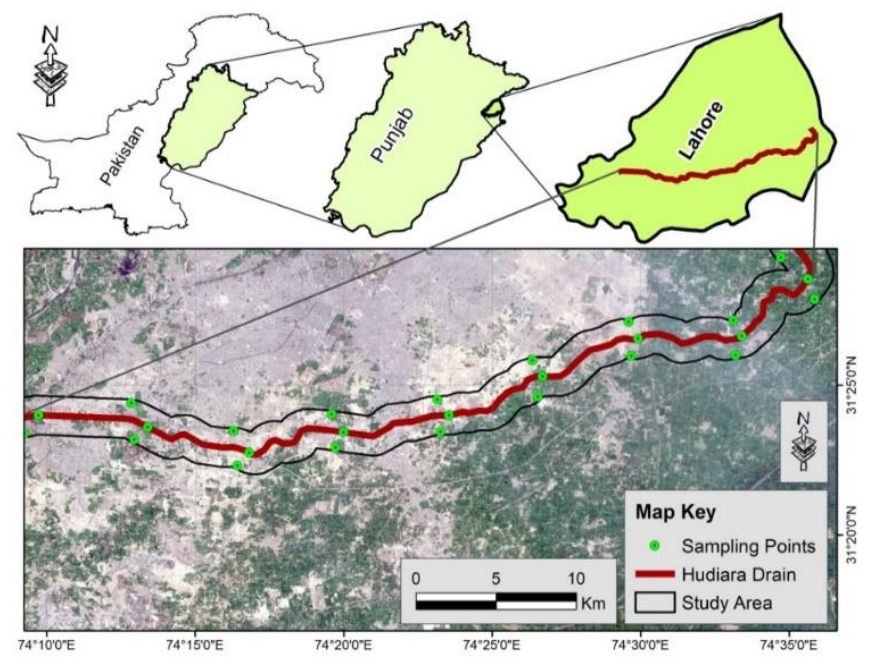

Figure 1. Study area and its associations.
In context of temperature and rainfall Lahore experiences large variations. It has very long and acute summer season, dry winters, and rainy monsoon season. On average it has annual rainfall of about $680 \mathrm{~mm}$, with peak from June to September (monsoon season). This region is part of interfluvial Bari Doab between, Sutlej and Ravi rivers (Muhammad et al., 2013). Geologically the study area formed over alluvial deposits of Quaternary period, with thickness varies maximum to $300 \mathrm{~m}$ and contains different types of rocks largely silt, sand and clay (Khattak et al., 2012).

Surroundings of HD are being used for agricultural, industrial, and residential purposes. Rice, wheat, maize, and potatoes are major crops of the area; however, some farmers also grow vegetables and fruits to meet their needs.

Soil and Drain Water Sampling and Analysis: Soil samples, from $0-15 \mathrm{~cm}$ depth, were collected along with their spatial coordinates in sets of nine. Each set was separated by about $6000 \mathrm{~m}$ from others and comprised of three composite samples: one near the HD, one to its right side within $1200 \mathrm{~m}$ and similarly one to its left side (Figure 1). In this way the data used comprised of 27 composite sample points. Collected soil samples were air-dried, ground, and sieved through $2 \mathrm{~mm}$ diameter. Known amount of each sample was wet digested with nitric acid and perchloric acid mixed in $2: 1$ volume ratio (Hseu, 2004). The digested contents were diluted to $50 \mathrm{~mL}$ volume and run-on Atomic Absorption Spectroscope (Model PG - 990) for $\mathrm{Cu}, \mathrm{Mn}, \mathrm{Zn}$ and Fe. The metal concentrations along with their spatial coordinates were used to create geographic layer in the form of shapefile for further spatial analysis.

From sites in drain, parallel to nine soil sampling set points, water samples were also collected in April (pre-monsoon) and October (post-monsoon), and analyzed for $\mathrm{Cu}, \mathrm{Fe}, \mathrm{Mn}$, and $\mathrm{Zn}$ on the same instrument as described in soil analysis.

\section{GIS Analysis}

Interpolation: As the measured metal concentrations in soil were location specific so, to make a continuous spatial distribution of the parameters, interpolated surfaces were generated over the study area that was extended to $1200 \mathrm{~m}$ on both sides of HD.

Among the deterministic families of interpolators Inverse Distance Weighted (IDW) is the simplest and the most used technique that is purely based on Tobler's first law of geography (Ketata-Rokbani et al., 2011; Bairu et al., 2013; Selvam et al., 2014; Mahmood et al., 2016). This law is stated as "Everything is related to everything else, but near things are more related than distant things". Geo-statistics and spatial autocorrelation are based upon this concept. More advanced interpolation techniques have been developed that are estimating parameter's values at un-sampled location with a better accuracy. Kriging family of interpolators is an example of such modern techniques that is recommended as a better alternate for creating continuous geographic layers from limited samples by recent studies (Alqadi et al., 2014; Taghizadeh-Mehrjardi, 2014; Mahmood et al., 2016).

In IDW sampled points nearer to locations of estimations get more importance in the estimating formula than those that are 
Table 1. Optimization of interpolation method on the basis of RMSE.

\begin{tabular}{|c|c|c|c|c|c|}
\hline \multirow{2}{*}{$\begin{array}{l}\text { Soil Quality Parameter } \\
\text { Zn }\end{array}$} & \multicolumn{2}{|c|}{ Transformation and data properties } & \multirow{3}{*}{$\begin{array}{l}\text { Optimal Interpolation Methods } \\
\text { Inverse Distance Weighted } \\
\text { Global Polynomial }\end{array}$} & \multirow{2}{*}{$\begin{array}{r}\text { Mean } \\
0.4226\end{array}$} & \multirow{3}{*}{$\begin{array}{l}\text { RMSE } \\
36.46 \\
36.80\end{array}$} \\
\hline & & \multirow[t]{2}{*}{$\log$} & & & \\
\hline & & & & 0.0673 & \\
\hline & \multirow[t]{2}{*}{ Skewness: } & \multirow[t]{2}{*}{0.2652} & Local Polynomial & 0.7032 & 37.66 \\
\hline & & & Radial Basis Function & 0.4928 & 36.81 \\
\hline & \multirow{2}{*}{ Kurtosis: } & \multirow{2}{*}{2.1136} & Ordinary Kriging with CSv & 0.0018 & 35.05 \\
\hline & & & Ordinary Kriging with SSv & 0.0663 & 35.05 \\
\hline & \multirow[t]{2}{*}{ 1st Quartile: } & \multirow[t]{2}{*}{4.2550} & Ordinary Kriging with ESv & 0.0537 & 35.03 \\
\hline & & & Ordinary Kriging with GSv & 0.0018 & 35.05 \\
\hline & Median: & 4.4362 & Simple Kriging with CSv & 0.9732 & 34.00 \\
\hline & & & Simple Kriging with SSv & 0.7982 & 34.06 \\
\hline & 3rd Quartile: & 4.8086 & Simple Kriging with ESv & 0.9951 & 34.29 \\
\hline & & & Simple Kriging with GSv & 0.9708 & 34.15 \\
\hline & Mean: & 4.5116 & Universal Kriging with CSv & -0.0018 & 35.05 \\
\hline & & & Universal Kriging with SSv & 0.0663 & 35.05 \\
\hline & Std div: & 0.3419 & Universal Kriging with ESv & 0.0538 & 35.03 \\
\hline & & & Universal Kriging with GSv & -0.0018 & 35.05 \\
\hline Te & Transformation: & Box-cox & Inverse Distance Weighted & -0.1476 & 24.93 \\
\hline & & & Global Polynomial & 1.9745 & 26.64 \\
\hline & Skewness: & -1.690 & Local Polynomial & -0.1533 & 24.48 \\
\hline & & & Radial Basis Function & 0.3580 & 27.01 \\
\hline & Kurtosis: & 6.159 & Ordinary Kriging with CSv & -0.0013 & 23.68 \\
\hline & & & Ordinary Kriging with SSv & -0.0112 & 23.74 \\
\hline & 1st Quartile: & 880.450 & Ordinary Kriging with ESv & -0.0023 & 23.80 \\
\hline & & & Ordinary Kriging with GSv & -0.0013 & 23.72 \\
\hline & Median: & 887.200 & Simple Kriging with CVg & 1.3996 & 22.71 \\
\hline & & & Simple Kriging with $\mathrm{SSv}$ & 0.9216 & 22.89 \\
\hline & 3rd Quartile: & 896.840 & Simple Kriging with ESv & 1.4231 & 22.78 \\
\hline & & & Simple Kriging with GSv & 0.9921 & 22.83 \\
\hline & Mean: & 884.970 & Universal Kriging with CSv & 0.0072 & 23.56 \\
\hline & & & Universal Kriging with SSv & 0.0132 & 23.63 \\
\hline & Std div: & 23.101 & Universal Kriging with ESv & 0.1150 & 23.62 \\
\hline & & & Universal Kriging with GSv & 1.0042 & 23.76 \\
\hline $\mathrm{Cu}$ & Transformation: & $\log$ & Inverse Distance Weighted & 0.3819 & 24.09 \\
\hline & & & Global Polynomial & -0.0455 & 24.18 \\
\hline & Skewness: & 0.8249 & Local Polynomial & 0.5468 & 25.30 \\
\hline & & & Radial Basis Function & 0.9851 & 25.64 \\
\hline & Kurtosis: & 2.7514 & Ordinary Kriging with CSv & -0.5731 & 22.91 \\
\hline & & & Ordinary Kriging with SSv & -0.5761 & 22.91 \\
\hline & 1st Quartile: & 3.4609 & Ordinary Kriging with ESv & -0.4685 & 22.89 \\
\hline & & & Ordinary Kriging with GSv & -0.5794 & 22.91 \\
\hline & Median: & 3.6623 & Simple Kriging with CSv & -0.3689 & 21.47 \\
\hline & & & Simple Kriging with $\mathrm{SSv}$ & 0.2075 & 22.11 \\
\hline & 3rd Quartile: & 3.9051 & Simple Kriging with ESv & 0.0348 & 22.15 \\
\hline & & & Simple Kriging with GSv & 0.0763 & 22.14 \\
\hline & Mean: & 3.7479 & Universal Kriging with CSv & -0.5731 & 22.91 \\
\hline & & & Universal Kriging with SSv & -0.5761 & 22.91 \\
\hline & Std div: & 0.4049 & Universal Kriging with ESv & -0.4685 & 22.89 \\
\hline & & & Universal Kriging with GSv & -0.5795 & 22.91 \\
\hline Mn & Transformation: & Box-cox & Inverse Distance Weighted & 0.9905 & 18.70 \\
\hline & & & Global Polynomial & -0.1369 & 19.84 \\
\hline & Skewness: & 0.457 & Local Polynomial & -1.1384 & 17.90 \\
\hline & & & Radial Basis Function & 0.7474 & 18.59 \\
\hline & Kurtosis: & 2.208 & Ordinary Kriging with CSv & -0.2449 & 17.47 \\
\hline & & & Ordinary Kriging with SSv & -0.2807 & 17.46 \\
\hline & 1st Quartile: & 83.400 & Ordinary Kriging with ESv & -0.2874 & 17.47 \\
\hline & & & Ordinary Kriging with GSv & -0.2563 & 17.47 \\
\hline & Median: & 95.000 & Simple Kriging with CSv & 0.2682 & 17.99 \\
\hline & & & Simple Kriging with SSv & 0.3279 & 18.01 \\
\hline & 3rd Quartile: & 117.560 & Simple Kriging with ESv & 0.4319 & 18.26 \\
\hline & & & Simple Kriging with GSv & 0.3532 & 17.98 \\
\hline & Mean: & 100.70 & Universal Kriging with CSv & -0.2449 & 17.47 \\
\hline & & & Universal Kriging with SSv & -0.2807 & 17.46 \\
\hline & Std div: & 25.852 & Universal Kriging with ESv & -0.2874 & 17.47 \\
\hline & & & Universal Kriging with GSv & -0.2563 & 17.47 \\
\hline
\end{tabular}

CVs: Circular Semiveriogram; SVg: Spherical semiveriogram; EVg: Exponential semiveriogram; GSv: Gausian semiveriogram

far apart, how much more importance they will get depends on the power value in the formula. Although default value of this power is 2 in almost all the software, but for better results this value should be optimized to natural setting and local 
conditions of the phenomenon. Likewise, there are different types of kriging i.e., ordinary, simple, and universal kriging, belongs to stochastic family of interpolators, that use different methods for surface estimation.

Further variations in kriging methods are being made by fitting various semi-variogram models i.e., circular, exponential etc. So, to make the best possible interpolated continuous surfaces of the metals' concentrations in soil all the interpolation techniques were tested for each metal by verifying the suitability using cross-validation. Crossvalidation provided values of mean as well as root mean square error (RMSE) to determine accuracy of the created surfaces. It is also worth mentioning here that almost all the interpolation methods assume that the sampled data is normally distributed. So, to comply with the assumption, the data was first checked for its distribution and transformed where needed. Normalized distribution was being standardized using the best values of skewness and kurtosis. Results of this exercise are provided in Table 1.

Analysis of proximity: To have spatial distribution patterns of soil $\mathrm{Cu}, \mathrm{Fe}, \mathrm{Mn}$ and $\mathrm{Zn}$, maps were prepared over a common scale. To check the study hypothesis that wastewater flowing in HD is controlling concentration of selected metals in surrounding soil, an additional spatial analysis of proximity was designed. For this analysis study area around the source was divided into 12 neighbors based on vertical distance from the source. Each of the zones was of $100 \mathrm{~m}$ radial distance from the source on both sides. Spatial distribution of proximity zones is shown in Fig. 2.

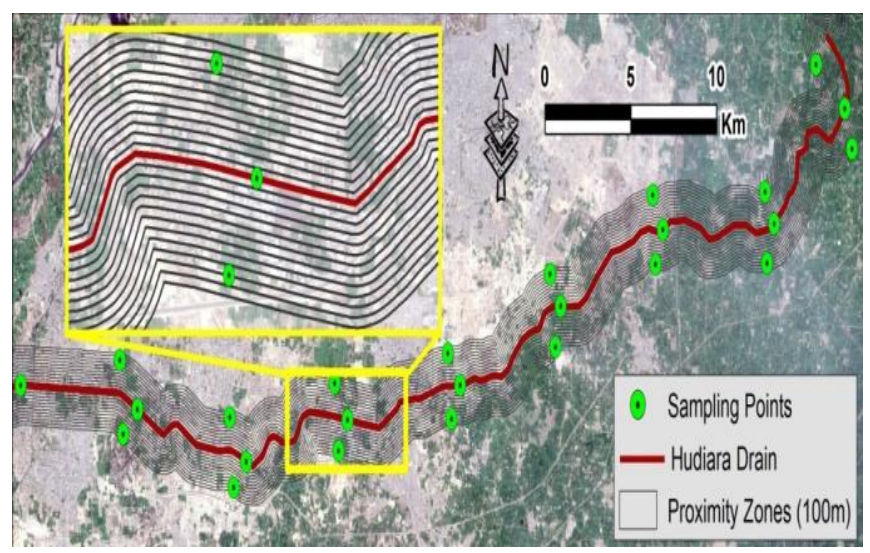

Figure 2. Spatial distribution of proximity zones.
Finally, the predicted values in each of the zones were averaged to reduce the effects of other contributory sources, and to get the pattern of distance dependent variations, if exists. Although this way of elongated zones averaging over both sides will surely result into very small variation of parametric values, but even then, it can be helpful to investigate dependence of variations over distance from the source. On the other hand, this averaging over large area is the only way to overcome any local variation that may exists at certain points along length of the area. In addition to the common scale maps of the averaging results, distance dependent variation profiles of the proximity analysis have also been prepared to explore trends and patterns of variation. To further remove effects of soil quality controlling sources other than HD, an additional trend function of EMA (Exponential Moving Average) was applied to the graphs of distance dependent variations. EMA is a moving average function that assigns weights to measured data values based on inverse distance law while estimation for a location. So, infect it is a momentum indicator that suppress insignificant anomalies, using weighted moving average function (Mahmood et al., 2017).

\section{RESULTS}

Permissible limits of $\mathrm{Cu}, \mathrm{Fe}, \mathrm{Mn}$ and $\mathrm{Zn}$ given in Table 2 shows that $\mathrm{Cu}$ and $\mathrm{Mn}$ concentrations were higher in some drain water samples, whereas $\mathrm{Fe}$ and $\mathrm{Zn}$ were found below guidelines in all the collected water samples. In September (post-monsoon season), possible dilution effect of monsoon season was not observed on these metal concentrations.

Spatial Distribution: Spatial distributions of soil $\mathrm{Cu}, \mathrm{Fe}, \mathrm{Mn}$ and $\mathrm{Zn}$ along the length of HD arranged in Fig. 3 reveal that $\mathrm{Zn}$ and $\mathrm{Cu}$ did not show any pattern that varies along the drain length. However, spot patterns of high and low values for both the parameters were almost similar (Fig. 3).

Intensity of total $\mathrm{Fe}$ in soil has been seen intensifying along downstream length of the source with maximum value in western edge of the study area where the drain falls into the River Ravi (Fig. 3). Spatial distribution of Mn shows that its intrusion into surrounding soils intensified just ahead of the middle of study area, whereas relatively less concentration was present at both eastern and western edges (Fig. 3).

Table 2. Metal concentrations in soil and Hudiara drain water samples. Metal Total conc. in soil (ppm) Conc. in drain water (ppm)

\begin{tabular}{ccccccc} 
& & & \multicolumn{2}{c}{ Pre-monsoon } & \multicolumn{2}{c}{ Post-monsoon } \\
\cline { 2 - 6 } & Range & Mean \pm SD & Range & Mean \pm SD & Range & Mean \pm SD \\
\hline $\mathrm{Cu}$ & $25-104$ & $46 \pm 22$ & $0.01-0.21$ & $0.06 \pm 0.056$ & $0.01-0.24$ & $0.09 \pm 0.09$ \\
$\mathrm{Fe}$ & $812-918$ & $886 \pm 23$ & $0.02-0.13$ & $0.08 \pm 0.04$ & $0.02-0.11$ & $0.07 \pm 0.04$ \\
$\mathrm{Mn}$ & $60-148$ & $102 \pm 26$ & $0.07-0.60$ & $0.26 \pm 0.18$ & $0.67-1.05$ & $0.84 \pm 0.11$ \\
$\mathrm{Zn}$ & $47-166$ & $96 \pm 34$ & $0.04-0.14$ & $0.07 \pm 0.03$ & $0.04-0.13$ & $0.06 \pm 0.03$ \\
\hline
\end{tabular}




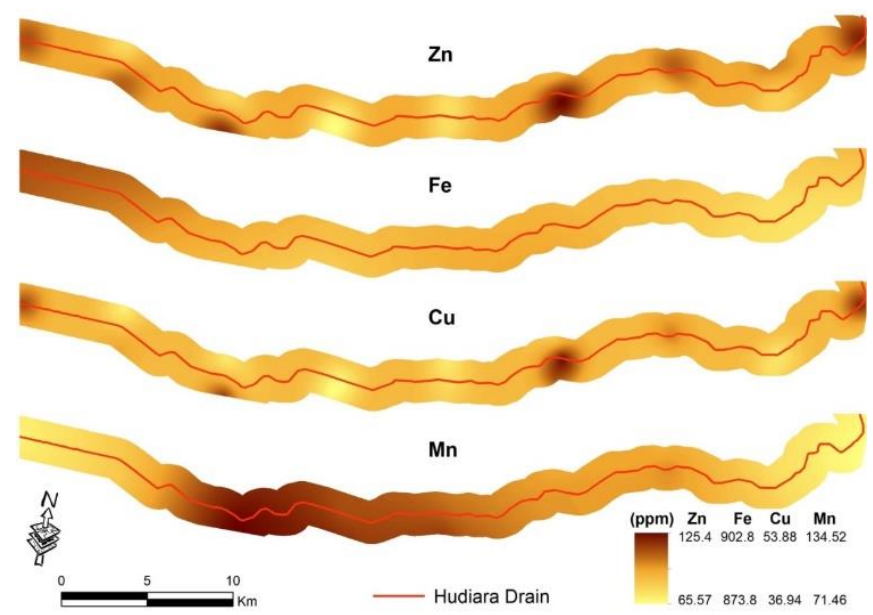

Figure 3. Spatial distribution of total $\mathrm{Cu}, \mathrm{Fe}, \mathrm{Mn}$ and $\mathrm{Zn}$ in soil along the length of Hudiara drain.

Proximity Analysis: Fig. 4 shows the results of proximity averaging of metal concentrations in soil with zoom-in at middle of the study area. As averaging was done along length of the study area so the resultant patterns of distant dependent variations away from the source were not only same but also the resultant variation was very small. For detailed insight into variations of soil $\mathrm{Cu}, \mathrm{Fe}, \mathrm{Mn}$ and $\mathrm{Zn}$ away from the source, distance dependent graphs of parametric averages are also given in Fig. 5.
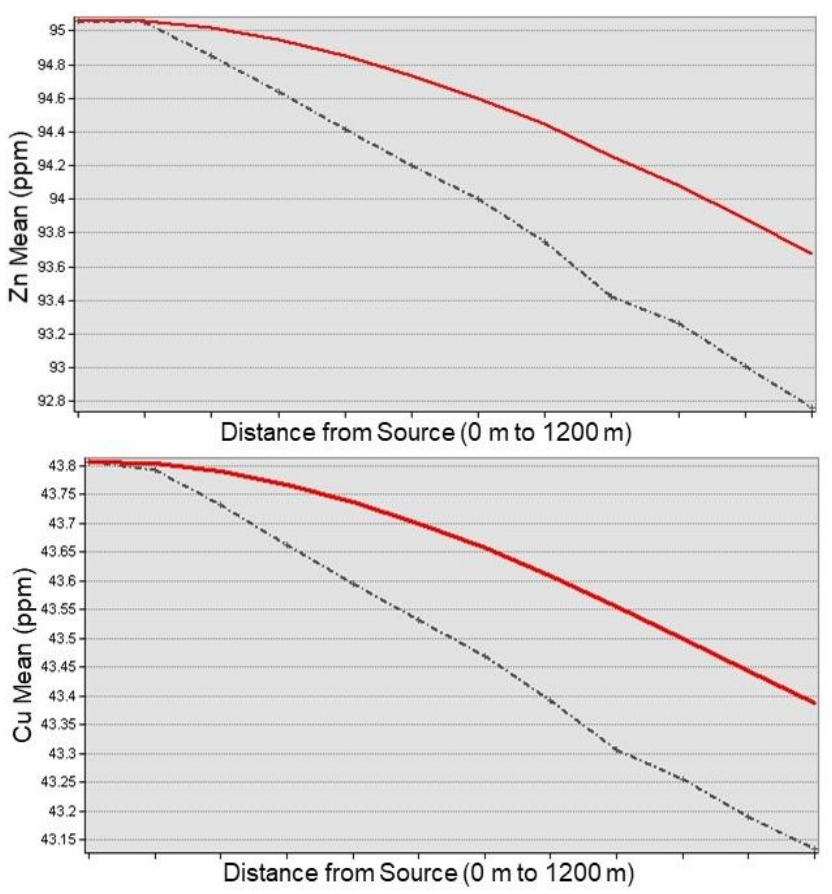

True Average

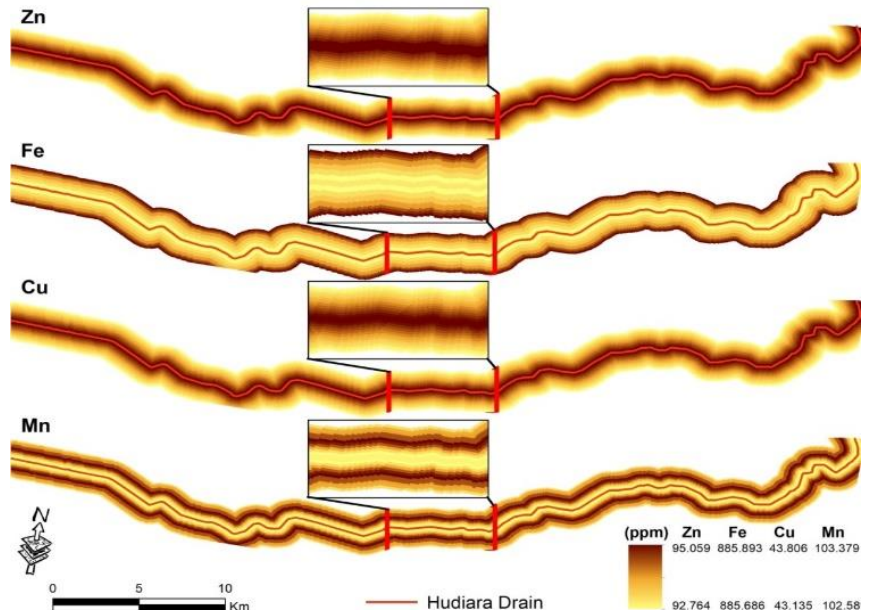

Figure 4. Results of the proximity stat analysis.

Both $\mathrm{Zn}$ and $\mathrm{Cu}$ are showing decrease in their average total concentration away from the source. However, the behaviour of Fe in going away from HD was entirely opposite to that of $\mathrm{Zn}$ and $\mathrm{Cu}$ and was increasing with distance away from the drain. Like that of $\mathrm{Fe}, \mathrm{Mn}$ concentration in soils was found increasing with distance away from HD. However, dilution effect lasts after about $900 \mathrm{~m}$ away from the drain and its concentration got independent of the distance from the source (Figure 4 and 5).
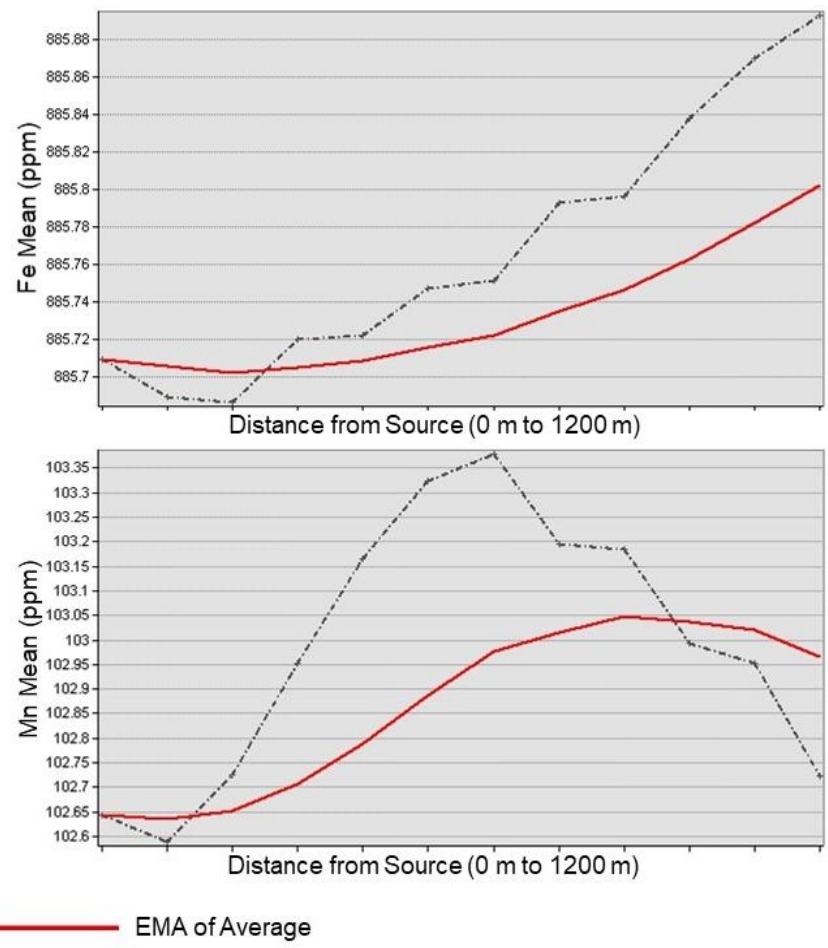

EMA of Average

Figure 5. Distance dependent vertical profiles of selected metals away from Hudiara drain. 


\section{DISCUSSION}

Common distribution spot pattern of $\mathrm{Cu}$ and $\mathrm{Zn}$ in soils seems to be due to common toxicity or deficiency of $\mathrm{Zn}$ and $\mathrm{Cu}$ in drain water used for irrigation as mean concentrations of both the metals were comparable to each other in drain water in pre-monsoon and post-monsoon seasons (Table 2). Besides direct irrigation, another possible way HD can contaminate surrounding agricultural land is through contaminating underground aquifer, which is then pumped for irrigation purposes (Khattak et al., 2012). Due to the influence of soil profile, both $\mathrm{Cu}$ and $\mathrm{Zn}$ can accompany each other in percolating water to reach aquifer. This hypothesis gets support from the fact that both the metals have synergistic effect on their extraction from soil to aqueous medium (Luo and Rimmer, 1995). In this interaction the effect of $\mathrm{Cu}$ on $\mathrm{Zn}$ solubility is more prominent than that of $\mathrm{Zn}$ on $\mathrm{Cu}$ (Luo and Rimmer, 1995).

There are several tributaries of HD and important ones are Minhala, Charrar, Ferozepur road and Sattu Katla drain. The Charrar drain meets HD at about the middle of our study area and might be a cause of $\mathrm{Mn}$ infestation in the surrounding before and after entering to HD. The drain Sattu Katla joins the HD near Bhobattian chowk on the Raiwind road. This is the same place where Mn concentration decreased and that of $\mathrm{Fe}$ increased in the surrounding soils. This indicates that Sattu Katla drain, running through Quaid-e-Azam industrial estate and carrying about $7500 \mathrm{~m}^{3} \mathrm{hr}^{-1}$ water to HD, causing a dilution of $\mathrm{Mn}$ and infestation of $\mathrm{Fe}$ in agricultural land surrounding HD. This hypothesis is supported by a Sattu Katla water quality report claiming mean concentration of $\mathrm{Fe}$ in water as $0.529 \mathrm{ppm}$ (Majeed et al., 2018), whereas overall average concentration of $\mathrm{Fe}$ in $\mathrm{HD}$ was $0.06 \mathrm{ppm}$ (Table 2). However, we found no report on Mn status of Sattu Katla and Charrar drains water.

When some source is responsible for intrusion of something in surrounding than maximum concentration of the intruded element has been found near the source and vice versa. According to this rule, the concentrations of $\mathrm{Cu}$ and $\mathrm{Zn}$ seem to be positively controlled by HD. On the other hand, total concentrations of $\mathrm{Fe}$ and $\mathrm{Mn}$ in soil were also very much dependent on the drain which tended to decrease it. This indicates that $\mathrm{HD}$ water has caused a dilution effect on $\mathrm{Fe}$ and Mn build up in the surrounding soils. This is possible because the soils already have a reasonable concentration of total $\mathrm{Fe}$ ranging from 812 to $918 \mathrm{ppm}$ with an average of $886 \mathrm{ppm}$ (Table 2), and the drain water was only slightly contaminated with the metal ( $0.08 \mathrm{ppm}$; Table 2$)$; the concentration was far below the permissible limit of $5 \mathrm{ppm}$ (WWF, 2007).

Conclusion: Our results oppose the general perception that drain water always add metals to soils, and management of metal micronutrients in the fertilizer plan is mostly neglected in drain-influenced soils. Instead, these soils also need site specific fertilizer recommendations for micronutrients along with macro nutrients.

\section{REFERENCES}

Alqadi, K.A., L. Kumar and H.M. Khormi. 2014. Mapping hotspots of underground water quality based on the variation of chemical concentration in Amman, Zarqa and Balqa regions, Jordan J. Earth Environ. Sci. 71:23092317.

Bairu, A., N. Tadesse and S. Amare. 2013. Use of geographic information system and water quality index to assess suitability of groundwater quality for drinking purposes in Hewane areas, Tigray, Northern Ethiopia. Ethiop. J. Environ. Stud. Manag. 6:110-123.

Hseu, Z.Y. 2004. Evaluating heavy metal contents in nine composts using four digestion methods. Bioresour. Technol. 95:53-59.

Kashif, S., M. Akram, M. Yaseen and S. Ali. 2009. Studies on heavy metals status and their uptake by vegetables in adjoining areas of Hudiara drain in Lahore. Soil Environ. 28:7-12.

Ketata-Rokbani, M., M. Gueddari and R. Bouhlila. 2011. Use of geographical information system and water quality index to assess groundwater quality in El Khairat deep aquifer (Enfidha, Tunisian Sahel). Iran J. Energy Environ. 2:133-144.

Khan, M., N. Khan and H. Aslam. 2003. Hudiara drain - a case of trans-boundary water pollution between India and Pakistan. Pak. J. Biol. Sci. 6:167-175.

Khattak, M.A., N. Ahmed, M.A. Qazi, A. Izhar, S. Ilyas, M.N. Chaudhary, M.S.A. Khan, N. Iqbal and T. waheed. 2012. Evaluation of ground water quality for irrigation and drinking purposes of the areas adjacent to Hudiara Industrial Drain, Lahore, Pakistan. Pak. J. Agric. Sci. 49:549-556.

Luo, Y. and D.L. Rimmer. 1995. Zinc-copper interaction affecting plant growth on a metal-contaminated soil. Environ. Pollut. 88:79-83.

Mahmood, K., A. Batool, F. Faizi, M.N. Chaudhry, Z. UlHaq, A.D. Rana and S. Tariq. 2017. Bio-thermal effects of open dumps on surroundings detected by remote sensing - Influence of geographical conditions. Ecol. Indic. 82:131-142.

Mahmood, K., Z. Ul-Haq, S.A. Batool, A.D. Rana and S. Tariq. 2016. Application of temporal GIS to track areas of significant concern regarding groundwater contamination. Environ. Earth Sci. 75:33.

Majeed, S., S. Rashid, A. Qadir, C. Mackay and F. Hayat. 2018. Spatial patterns of pollutants in water of metropolitan drain in Lahore, Pakistan, using multivariate statistical techniques. Environ. Monit. Assess. 190:1-15. 
Muhammad, H., Z. Iqbal, M. Ayub and M.A. Malik. 2013. Uptake of heavy metals by Brassica compestris, irrigated by hudiara drain in Lahore, Pakistan. Can. J. Pure Appl. Sci. 7:2599-2604.

Osman, K.T. 2013. Plant nutrients and soil fertility management. In Soils. Springer.pp. 129-159.

Qureshi, A. and A.H. Sayed. 2014. Situation analysis of the water resources of Lahore -establishing a case for water stewardship. WWF-Pakistan. pp. 1-34.

Ryan, J., A. Rashid, J. Torrent, S.K. Yau, H. Ibrikci, R. Sommer and E.B. Erenoglu. 2013. Micronutrient constraints to crop production in the Middle East-west Asia region: Significance, research, and management. In Advances in agronomy. Elsevier. pp.1-84.

Selvam, S., G. Manimaran, P. Sivasubramanian, N. Balasubramanian and T. Seshunarayana. 2014. GISbased evaluation of water quality index of groundwater resources around Tuticorin coastal city, South India. Environ. Earth Sci. 71:2847-2867.

Shah, F.R., N. Ahmad, D.M. Zahid, K.R. Masood and S.S. Ahmad. 2010. The Hudiara drain wastewater effect on the distribution of surrounding herbaceous vegetation. Pak. J. Bot. 42:1745-1754.

Shakir, S.K., A. Azizullah, W. Murad, M.K. Daud, F. Nabeela, H. Rahman, S. ur-Rehman and D.P. Häder. 2016. Toxic metal pollution in Pakistan and its possible risks to public health. In Reviews of Environmental Contamination and Toxicology Volume 242. Springer. pp. 1-60.

Taghizadeh-Mehrjardi, R. 2014. Mapping the spatial variability of groundwater quality in Urmia, Iran. J. Mater. Environ. Sci. 5:530-539.

Wuana, R.A. and F.E. Okieimen. 2011. Heavy metals in contaminated soils: a review of sources, chemistry, risks and best available strategies for remediation. ISRN Ecol. $1-15$.

WWF. 2007. National surface water classification criteria \& irrigation water quality guidelines for Pakistan. WWFPakistan, Lahore, Pakistan.

Yamin, M.T. and N. Ahmad. 2007. Influence of Hudiara drain water irrigation on trace elements load in soil and uptake by vegetables. J. Appl. Sci. Environ. Manag. 11:169-172. 